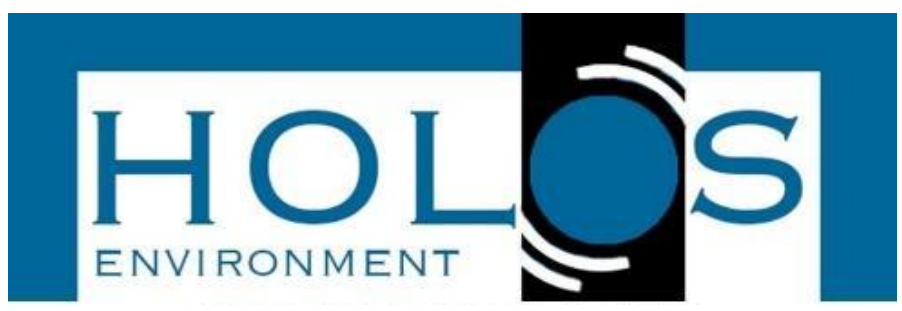

\title{
INFLUÊNCIA DO USO DO SOLO NA TAXA DE INFILTRAÇÃO DA ÁGUA NA BACIA HIDROGRÁFICA DOS IGARAPÉS 54 E 7, PARAGOMINAS/PA
}

\section{INFLUENCE OF LAND USE ON THE WATER INFILTRATION RATE IN THE HYDROGRAPHIC BASIN OF THE STREAMS 54 AND 7, PARAGOMINAS/PA}

\author{
Paulo Galvão ${ }^{1}$
}

Artigo recebido em: 23/03/2020 e aceito para publicação em: 16/04/2020. DOI: http:/dx.doi.org/10.14295/holos.v20i2.12382

\begin{abstract}
Resumo: A infiltração é o fenômeno em que a água penetra no perfil do solo devido a este meio ser permoporoso, ou por capilaridade em solos pouco permeáveis. Se a percolação for mais profunda, a água contribuirá com a recarga do aquífero local. A taxa de infiltração pode ser diferente a depender do tipo e do uso e ocupação do solo, da cobertura vegetal (ou ausência dela) ou do grau de compactação do terreno (natural ou antropicamente induzido). O município de Paragominas, sudoeste do Pará, possui locais em que a combinação de diferentes tipos de solo, cobertura vegetal, manejo e de manutenção da mata ciliar podem resultar em diferentes taxas de infiltração da água, afetando na recarga dos aquíferos locais. A pesquisa avaliou possíveis mudanças nas taxas de infiltração de água em áreas de mata ciliar, pastagem e agricultura no igarapé 54 e no igarapé 7 e as comparou com os períodos seco e chuvoso. Parâmetros como granulometrias e teores de umidade de cada solo foram igualmente avaliados. Constatou-se uma estreita relação entre taxa de infiltração, teor de umidade, textura e tipo de manejo do solo. Em mata ciliar, o caráter argiloso do terreno e o papel da vegetação foram determinantes no baixo valor de infiltração; em pastagem, houve valores distintos de infiltração entre a seca e a chuva devido à baixa capacidade de retenção de umidade na camada superficial do solo, além da compactação devido ao pisoteio do gado; na área de agricultura (apenas no igarapé 54) houve um comportamento próximo nas duas estações, com a taxa de infiltração estabilizando aos 60 minutos.
\end{abstract}

Palavras-chave: Infiltração. Solo. Água subterrânea. Paragominas. Pará.

\begin{abstract}
Infiltration is the phenomenon in which water penetrates in the soil profile due to it being permoporous, or due to capillarity in non-permeable soils. If the percolation is deeper, the water will contribute to the recharge of the local aquifer. The infiltration rate may be different depending on the type and use and occupation of the soil, the vegetation cover (or lack thereof) or the degree of soil compaction (natural or anthropically induced). The municipality of Paragominas, southwest of Pará, has regions where the combination of different types of soil, vegetation cover, management and maintenance of riparian forest can result in different water infiltration rates, affecting local aquifer recharges. The research evaluated possible changes in the water infiltration rates in the soil in riparian forest, pasture and agriculture areas in the stream 54 and stream 7 comparing them with the dry and rainy periods. Parameters such as granulometry and moisture content of each soil were also analyzed. There was a close relationship between infiltration rate, moisture content, texture and type of soil management. In the riparian forest, the clay type of the soil and the role of vegetation were decisive in low values of infiltration; in the pasture, there were different values of infiltration between drought and rainy seasons, due to the low capacity of moisture retention in the superficial layer of the soil, in addition to compaction due to the trampling of cattle; in the agriculture area (only in stream 54) there was a similar behavior in both seasons, with infiltration rate stabilizing at 60 minutes.
\end{abstract}

Keywords: Infiltration. Soil. Groundwater. Paragominas, Pará.

\footnotetext{
${ }^{1}$ Universidade Federal de Minas Gerais (UFMG), Belo Horizonte, MG. E-mail: (hidropaulo@gmail.com)
} 


\section{INTRODUÇÃO}

O desmatamento e queimadas desordenadas, o uso irregular e excessivo de agrotóxicos e/ou adubos químicos aceleram o ritmo da erosão, o assoreamento de reservatório de água, a degradação da qualidade das águas superficiais e subterrâneas, além da inundação em campos e cidades ribeirinhas do norte do país. Dependendo do tipo de cultura instalada e do manejo de solo, pode haver grande exposição da superfície do solo à ação erosiva das chuvas. Além disso, com a formação de enxurradas, há o carreamento de grande quantidade de sedimentos para cursos d'água, em maior ou menor intensidade, de acordo com as características do solo, topografia, chuva, entre outras (BERTONI \& LOMBARDI NETO, 1990, TUCCI \& CLARKE 1997, FEITOSA et al., 2008).

A infiltração é o fenômeno pelo qual a água superficial penetra no perfil do solo, onde só é possível pelo fato desse meio ser permoporoso. Inicialmente, a taxa de infiltração é elevada, diminuindo com o tempo até ficar constante quando o solo fica totalmente saturado, alcançando sua capacidade de campo (LIBARDI 1995, TUCCI 2004, FEITOSA et al., 2008). Para as águas subterrâneas, o carreamento de partículas finas pode interferir no processo de infiltração da água no solo, afetando a recarga dos aquíferos. Dependendo da composição textural do solo, da cobertura vegetal (ou da ausência dela), teor de umidade, e até o grau de compactação do terreno (podendo ser natural ou induzido por atividades antrópicas, como pisoteio de gado devido a atividades agropecuárias) pode implicar na modificação da estrutura do solo, fator importante no processo de infiltração da água nesse meio (SOBRINHO et al., 2003).

Há diversos dispositivos de medição in situ da taxa de infiltração do solo, que incluem infiltrômetros de anel (cilindro) único e de cilindro duplo, permeâmetros Philip-Dunne e de Guelph e infiltrômetro de tensão. As descrições mais detalhadas de cada técnica, incluindo métodos e pós-processamento, bem como vantagens e desvantagens de cada método, podem ser vistas em Bouwer (1986), ASTM D3385 (2003), Gulliver et al. (2010) e Walsh \& McDonnell (2012).

A modificação da taxa de infiltração da água no solo tem levado a conscientização de diversos setores da sociedade no que concerne à necessidade de proteção dos solos e das águas. O emprego de práticas conservacionistas de uso da terra vem sendo adotado em vários tipos de cultivos, como soja/milho, em diversas regiões. Tais práticas, além de proteger o solo, visam eliminar/controlar queimadas, manter/melhorar a fertilidade do solo, propiciar a infiltração de água no terreno e, consequentemente, a recarga do lençol freático. 
As queimadas, quando com frequência, deixam o solo exposto aumentando a erosão. A queima dos resíduos vegetais diminui a matéria orgânica do solo, enfraquece a sua estrutura e, com isso, aumenta a susceptibilidade à erosão (BERTOL et al., 2004).

No caso de Paragominas, sudoeste do Pará, as queimadas são comumente utilizadas como meio rápido e econômico de limpar o terreno, de combater pragas das culturas e de renovar pastagens. Tecnologias alternativas vêm sendo usadas, com destaque para o plantio direto, o manejo de capoeira e a manutenção de matas ciliares, em contraste com práticas tradicionais de aradura e gradagem. $O$ sistema de rotação de culturas também é praticado na região, alternando culturas de soja, milho, algodão e arroz. O plantio direto tem-se caracterizado por apresentar, na camada de 0 a $20 \mathrm{~cm}$ de profundidade, maior estabilidade estrutural, maior densidade do solo, menor porosidade total e macroporosidade, em comparação com outros sistemas de preparo do solo (STONE \& MOREIRA, 2000).

Devido a essas questões, Paragominas possui locais em que combinações diferentes de tipos de solo, cobertura vegetal, tipos de manejo e de manutenção da mata ciliar podem resultar em diferentes taxas de infiltração da água no solo, afetando, consequentemente, na recarga posterior dos aquíferos locais. Sendo assim, o objetivo desse estudo é avaliar possíveis mudanças no processo de infiltração de água no solo em áreas preparadas para cultivo de soja e milho, de pasto, e de mata ciliar nas bacias hidrográficas do igarapé 54 e do igarapé 7 . Procurou-se, também, relacionar os resultados obtidos com a forma de uso do solo e com as características litológicas do terreno. Assim, buscou-se avaliar qual do tipo de ocupação provoca maior alteração na taxa de infiltração, comparando-se, ainda, os dados obtidos com aqueles trabalhos anteriormente executados na região.

\section{MATERIAIS E MÉTODOS}

\subsection{Caracterização da Área de Estudo}

O município de Paragominas, pertencente à microrregião Guajarina, está situado na porção sudeste do Pará. Possui área territorial aproximada de $19.700 \mathrm{~km}^{2}$ e está a $285 \mathrm{~km}$ de Belém, capital do Pará. A área de estudo localiza-se na Fazenda Vitória, a 6 km ao norte da cidade de Paragominas. A fazenda de 3.500 ha. é um mosaico de floresta primária, floresta secundária (ou capoeira), pastagem recuperada e pastagem degradada, tendo 
grande parte de sua área de floresta submetida a cortes em 2001. Dentro dos limites da Fazenda Vitória estão os igarapés 54 e 7 (Figura 1).

Geologicamente, Paragominas pertence à Bacia do Maranhão, conforme definição de Mesner \& Wooldridge (1964). Contudo, Góes (1981) admitiu uma evolução policiclíca para esta extensa Província Sedimentar, possibilitando sua compartimentação em diferentes bacias, denominadas de Parnaíba, Alpercatas, Grajaú e Espigão-Mestre. Nessa nova conceituação, a região situa-se na bacia do Grajaú, cuja estratigrafia é identificada, da base para o topo, pelas seguintes unidades geológicas: formações Itapecuru e Ipixuna, coberturas detrito-lateríticas paleogênicas e depósitos aluviais.

A Formação Itapecuru abrange toda a área urbana e periurbana do município e é composta por arenitos róseos ou avermelhados, argilosos, finos e grosseiros, contendo estratos cruzados abundantes, sotopostos por um manto laterítico rico em material ferruginoso. Dados de sondagem elétrica vertical (SEV) mostram que a espessura desta unidade pode chegar a 450 m (CPRM, 1997). A Formação Ipixuna representa uma sucessão de arenitos e siltitos, com uma litofácie inferior constituída por arenitos finos e siltitos ritmicamente interrelacionados, e outra superior onde predominam terrenos arenosos, com abundantes estratificações cruzadas e subordinadas, com intercalações de siltitos, além de horizontes de argilas cauliníticas, as quais mostram certa similaridade com os sedimentos da Formação Itapecuru (GÓES 1981, RODRIGUES et al., 2002).

As coberturas detrito-lateríticas paleogênicas ocorrem como capeamentos da Formação Ipixuna (IBGE 1996). Essa unidade exibe um perfil laterítico completo, descrito por Costa et al. (1985), ocorrendo da base para o topo horizontes argilosos e mosqueados, culminando com uma espessa crosta laterítica aluminosa, que representam as principais jazidas de caulim e bauxita do território brasileiro. Na parte superior ocorre um nível mais argiloso denominado "Argila de Belterra" (RODRIGUES et al. 2002). Por fim, os depósitos aluviais quaternários estão localizados no vale dos rios Capim e Gurupi e exibem, em alguns trechos, terraços de idade Pleistocênica (IBGE, 1996).

O clima é tropical chuvoso sem estação fria e com temperaturas médias mensais acima de $18^{\circ} \mathrm{C}$. A temperatura média anual é de $26,5^{\circ} \mathrm{C}$ e o regime pluviométrico está, geralmente, entre 2.250 e 2.500 mm/ano. As chuvas, apesar de regulares, não se distribuem igualmente durante o ano, sendo de janeiro a junho a maior concentração ( 80\%), implicando grandes excedentes hídricos e, consequentemente, grandes escoamentos superficiais e cheias dos rios. A umidade relativa do ar está em torno de $85 \%$ (PINTO et al., 2009). 
Devido ao clima local, a vegetação é caracterizada pela Floresta Equatorial Subperenifólia Densa Submontana, Densa das Terras Baixas e Densa Aluvial. Era representada pela Floresta Densa da sub-região dos Altos Platôs do Pará-Maranhão, pela Floresta Densa de Planície Aluvial e dos Terraços. Entretanto, os constantes desmatamentos na região, principalmente de atividades agrícolas, extrativas e madeireiras, reduziram drasticamente as grandes áreas cobertas pela floresta original, dominadas, hoje, por áreas de vegetação secundária (SECTAM 1996). Quanto à pedologia, o solo da região é do tipo Latossolo amarelo caulinítico altamente intemperizado, com teor de argila de 50 a $80 \%$, originados da "Argila de Belterra", desenvolvida no topo e declive superiores de terraços, durante o Pleistoceno. Há presença de solos aluviais e solos indiscriminados nas áreas de várzea.

Existem vários rios importantes na região. Na porção SE-NE está o rio Gurupi, que separa os estados do Pará e do Maranhão. O rio Capim é outro curso d'água de grande importância, servindo de limite entre Paragominas e São Domingos do Capim. O rio Uraim drena a sede do município a noroeste. Na área de estudo, os igarapés 54 e 7 são afluentes dos rios Cipó e Uraim, respectivamente, tributários da Bacia do Gurupi, que limita os estados do Pará e Maranhão ao norte, até alcançar o oceano Atlântico.

A CPRM concluiu, em 1997, uma pesquisa hidrogeológica nos bairros de Trecho Seco e Jardim Atlântico, na cidade de Paragominas. A geofísica, por meio SEVs, revelou a localização do sistema aquífero existente na Formação Itapecuru, denominado, formalmente, de Aquífero Itapecuru. As zonas saturadas variam entre 40 e $80 \mathrm{~m}$ de profundidade, controladas pela topografia local e constituem-se nas faixas mais promissoras à captação de água subterrânea para abastecimento público. Foi comprovado que nessas áreas e arredores os sedimentos da Formação Itapecuru são submetidos a induções diretas de recarga, via precipitações pluviométricas e do rio Uraim que corta a cidade de Paragominas. A vazão de poço tubular perfurado nesse aquífero, após a conclusão dos trabalhos de perfuração foi de $34,7 \mathrm{~m}^{3} / \mathrm{h}$, a uma profundidade final de $80 \mathrm{~m}$ (CPRM 1997). 
Figura 1- Acesso e localização do município de Paragominas, sudoeste do Pará, bem como localização dos igarapés 54 e 7 , foco de estudo dessa pesquisa

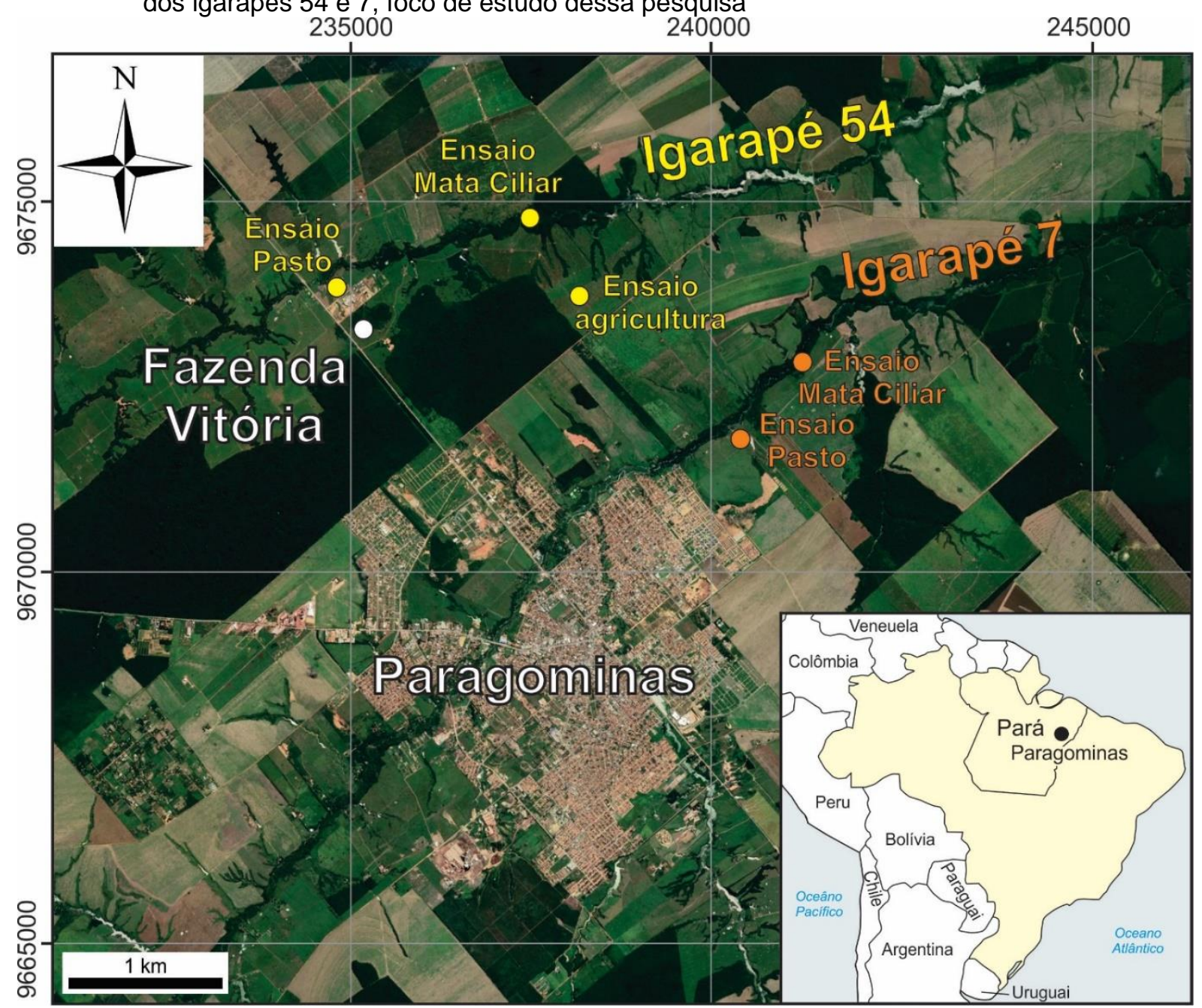

Fonte: Modificado de Google Earth.

\subsection{Métodos Utilizados}

Realizou-se um total de 10 ensaios de infiltração, divididos em 5 ensaios na estiagem e 5 ensaios no período chuvoso. Os ensaios foram realizados em área de pasto, de agricultura e mata ciliar na região do igarapé 54 e área de pasto e mata ciliar na região do igarapé 7. Não foi possível fazer ensaio de infiltração em área de agricultura na região do igarapé 7, pois não havia esse tipo de cultura.

Para a determinação da taxa de infiltração do solo foi utilizado um infiltrômetro de cilindro duplo que consiste em cilindros de chapa metálica, com $30 \mathrm{~cm}$ de altura e diâmetros de $20 \mathrm{~cm}$ e $30 \mathrm{~cm}$. Esses cilindros foram cravados verticalmente no solo, de forma concêntrica, a cerca de $10 \mathrm{~cm}$ de profundidade, de acordo com Bouwer (1986). Durante o ensaio de infiltração, foi aplicada água no cilindro interior e no espaço anular entre o cilindro 
maior e menor. O objetivo do cilindro externo é garantir a verticalidade do fluxo, gerando assim uma parede de umidade em torno do cilindro interno.

A leitura da variação do nível da água ao longo do tempo foi feita com o auxílio de uma régua. As leituras foram realizadas nos seguintes tempos: 1, 2, 3, 5, 10, 20, 30, 40, 60, 90, 120, conforme Cauduro \& Dorfiman (1986). Com os valores das leituras nos tempos pré-determinados e das diferenças do rebaixamento do nível d'água ( $\left.h=h_{n}-h_{n}-1\right)$ para as diferenças de tempo correspondentes $\left(t=t_{n}-t_{n}-1\right)$, calculou-se a velocidade de infiltração $\left(\mathrm{V}_{\mathrm{i}}\right)$ para cada um daqueles instantes: $\mathrm{V}_{\mathrm{i}}=\Delta \mathrm{h} / \Delta \mathrm{t}{ }^{*} 60=\mathrm{h}_{\mathrm{n}}-\mathrm{h}_{\mathrm{n}}-1 / \mathrm{t}_{\mathrm{n}}-\mathrm{t}_{\mathrm{n}}-1{ }^{*} 60$

Concomitantemente aos ensaios, realizou-se a amostragem de materiais inconsolidados visando a obtenção dos índices físicos em ensaios de laboratório, feitos no Instituto de Geociências da Universidade Federal do Pará. Foram coletadas, próximas aos cilindros, amostras de sedimentos com uso de trado manual a cada $30 \mathrm{~cm}$ de profundidade e guardadas em recipientes especiais para manter a umidade para determinação do teor de umidade do solo e para a caracterização granulométrica por meio do peneiramento (frações mais grossas - 2,0 mm e $<0,062 \mathrm{~mm}$ ) e decantação por centrifugação (frações inferiores a 0,062 mm), conforme procedimentos descritos na norma ABNT 7217 (1987).

Para determinar o teor de umidade do solo, o procedimento consistiu em pesar as amostras úmidas e, em seguida, colocá-las em uma estufa a $100^{\circ} \mathrm{C}$ para secar. Posteriormente, a amostra, já seca, foi pesada novamente e a partir da diferença de peso entre a amostra úmida e seca foi determinado o teor de umidade do solo no momento do ensaio.

\section{RESULTADOS E DISCUSSÃO}

\subsection{Análise Granulométrica e Umidade do Solo - Igarapé 54}

Mata Ciliar: nos primeiros $30 \mathrm{~cm}$ de solo, houve um predomínio de sedimentos de granulometria silte/argila, os quais totalizaram 70,65\% da amostra; por sua vez, as frações areia fina, muito fina e areia média corresponderam a 25,58 e 3,35\%, respectivamente. As frações areia grossa, muito grossa e grânulo alcançaram valores pouco representativos, de $0,42 \%$ (Tabela 1$)$.

Pastagem: nos primeiros $30 \mathrm{~cm}$ de solo, os sedimentos de granulometria silte/argila também foram predominantes, correspondendo a 60,65\%. A fração areia fina/muito fina, 
totalizando 25,72\%, foi muito próxima da obtida para a área de mata ciliar; por outro lado, as frações areia média e grossa/muito grossa e grânulo, representando 8,5 e 5,13\%, respectivamente, se mostraram mais elevadas do que as obtidas na área de mata ciliar (Tabela 1).

Agricultura: nos primeiros $30 \mathrm{~cm}$ de solo, houve, também, predomínio de sedimentos de granulometria silte/argila, atingindo 55,97\%. A fração areia fina/muito fina alcançou valores maiores do que os obtidos na área de pasto, 36,9\%. A fração areia média totalizou 5,31\%, enquanto as frações areia grossa/muito grossa e grânulo alcançaram valores pouco representativos, de 1,82\% (Tabela 1 ).

Com relação ao teor de umidade do solo, em todas as áreas, a umidade foi menor no período de estiagem. A mata ciliar apresentou maior umidade global em relação às outras áreas estudadas, sendo que a de agricultura indicou uma maior variação de umidade entre a seca e o período chuvoso (Tabela 2). Essa variação pode ser explicada pela diferença no teor de argila/silte no solo entre as áreas, onde a mata ciliar tem 80,7\%, a pastagem $75,4 \%$ e a agricultura $54,6 \%$, sendo esta última mais permoporosa em comparação às outras.

Tabela 1 - Análise granulométrica do solo do igarapé 54 para mata ciliar, pastagem e agricultura

\begin{tabular}{lcccc}
\hline Partícula & Diâmetro $(\mathbf{m m})$ & $\begin{array}{c}\text { Mata ciliar } \\
\text { Peso (\%) }\end{array}$ & $\begin{array}{c}\text { Pastagem } \\
\text { Peso (\%) }\end{array}$ & $\begin{array}{c}\text { Agricultura } \\
\text { Peso (\%) }\end{array}$ \\
\hline Grânulo & $>2.000$ & 0,01 & 0,35 & 0,8 \\
Areia muito grossa & $2.000-1.416$ & 0,03 & 0,8 & 0,14 \\
Areia grossa & $1.416-1.000$ & 0,1 & 0,98 & 0,21 \\
Areia média & $1.000-0.710$ & 0,08 & 1,48 & 0,27 \\
& $0.710-0.500$ & 0,2 & 1,52 & 0,4 \\
Areia fina & $0.500-0.350$ & 0,38 & 2,52 & 1,6 \\
& $0.350-0.250$ & 2,97 & 5,98 & 3,71 \\
Areia muito fina & $0.250-0.177$ & 9,48 & 12,82 & 14,29 \\
Argila/silte & $0.177-0.125$ & 7,1 & 6,0 & 10,94 \\
Total & $0.125-0.088$ & 5,88 & 5,1 & 7,75 \\
\hline
\end{tabular}


Tabela 2 - Teor de umidade do solo do igarapé 54 para mata ciliar, pastagem e agricultura para os períodos seco e chuvoso

\begin{tabular}{cccc}
\hline \multirow{2}{*}{ Igarapé 54 } & \multirow{2}{*}{ Argila/silte (\%) } & \multicolumn{2}{c}{ Teor de umidade (\%) } \\
& & Estiagem & Chuvoso \\
\hline Mata Ciliar & 80,7 & 25,5 & 28,9 \\
Pastagem & 75,4 & 14,2 & 22,2 \\
Agricultura & 54,6 & 9,0 & 16,9 \\
\hline
\end{tabular}

\subsection{Análise Granulométrica e Umidade do Solo - Igarapé 7}

Mata Ciliar: houve o predomínio de sedimentos de granulometria silte/argila, com 57,34\%. As frações areia fina, muito fina e média ficaram em $29,37 \%$ e 9,85\%, respectivamente. As frações areia grossa, muito grossa e grânulo alcançaram valores baixos, em torno de $3,44 \%$ (Tabela 3).

Pastagem: nos primeiros $30 \mathrm{~cm}$ de solo, houve o predomínio da granulometria silte/argila de $30,81 \%$. A fração areia fina/muito fina foi $39,55 \%$. A fração areia média totalizou $20,68 \%$, enquanto as frações areia grossa, muito grossa e grânulo alcançaram valores incipientes, de $8,96 \%$ (Tabela 3).

Com relação ao teor de umidade do solo, assim como no igarapé 54 , em todas as três áreas a umidade foi menor no período de estiagem. A mata ciliar apresentou maior umidade global em relação à área de pastagem, sendo está última com considerável variação no teor de umidade entre a seca e o período chuvoso, de $8,7 \%$ para $21,6 \%$; isso pode ser também explicado pela diferença no teor de argila/silte no solo, onde a mata ciliar tem $67,9 \%$ e a pastagem tem apenas $29,5 \%$, portanto, mais permoporosa (Tabela 4 ).

Tabela 3 - Análise granulométrica do solo do igarapé 7 para as áreas de mata ciliar e pastagem.

\begin{tabular}{lccc}
\hline Partícula & Diâmetro $(\mathbf{m m})$ & $\begin{array}{c}\text { Mata ciliar } \\
\text { Peso (\%) }\end{array}$ & $\begin{array}{c}\text { Pastagem } \\
\text { Peso (\%) }\end{array}$ \\
\hline Grânulo & $>2.000$ & 0,12 & 0,12 \\
Areia muito grossa & $2.000-1.416$ & 0,17 & 0,6 \\
Areia grossa & $1.416-1.000$ & 0,43 & 1,23 \\
Areia média & $1.000-0.710$ & 0,76 & 2,63 \\
& $0.710-0.500$ & 1,96 & 4,38 \\
Areia fina & $0.500-0.350$ & 2,5 & 7 \\
& $0.350-0.250$ & 7,35 & 13,68 \\
Areia muito fina & $0.250-0.177$ & 10,86 & 18,84 \\
Argila/silte & $0.177-0.125$ & 8,22 & 9,35 \\
Total & $0.125-0.088$ & 7 & 8,26 \\
\hline
\end{tabular}


Tabela 4 - Teor de umidade do solo do igarapé 7 para mata ciliar, pastagem e agricultura para os períodos seco e chuvoso.

\begin{tabular}{cccc}
\hline \multirow{2}{*}{ Igarapé 7 } & \multirow{2}{*}{ Argila/silte (\%) } & \multicolumn{2}{c}{ Teor Umidade (\%) } \\
& & Estiagem & Chuvoso \\
\hline Mata Ciliar & 67,9 & 29,7 & 32,9 \\
Pastagem & 29,5 & 8,7 & 21,6 \\
\hline
\end{tabular}

\subsection{Ensaios de Infiltração em Mata Ciliar - Igarapé 54 e 7}

O ensaio feito no igarapé 54 na estiagem (Figura 2), com predomínio de solo argiloso ( $80,7 \%$ de argila/silte) e teor de umidade de $25,5 \%$, apresentou valor máximo de velocidade instantânea $\left(V_{i}\right)$ de $0,038 \mathrm{~mm} / \mathrm{s}$ e mínimo de $0,016 \mathrm{~mm} / \mathrm{s}$, com velocidade de infiltração estabilizando logo no quarto minuto $\left(\mathrm{V}_{i}=0 \mathrm{~mm} / \mathrm{s}\right)$. No ensaio feito no período chuvoso (Figura 2), o teor de umidade do solo foi de $28,9 \%$ e velocidade instantânea $\left(V_{i}\right)$ de 0,283 $\mathrm{mm} / \mathrm{s}$ no primeiro minuto, estabilizando-se logo em seguida $\left(V_{i}=0 \mathrm{~mm} / \mathrm{s}\right)$.

O ensaio feito no igarapé 7 na estiagem (Figura 2), com predomínio de solo argiloso (67,9\% de argila/silte) e teor de umidade em torno de 29,7\%, teve valor máximo de velocidade instantânea $\left(V_{i}\right)$ de $0,150 \mathrm{~mm} / \mathrm{s}$ e mínimo de $0,016 \mathrm{~mm} / \mathrm{s}$, com velocidade de infiltração estabilizando-se no quarto minuto $\left(V_{i}=0 \mathrm{~mm} / \mathrm{s}\right)$. No ensaio feito no período chuvoso (Figura 2), o teor de umidade do solo foi de $32,9 \%$ e o valor de velocidade instantânea $\left(\mathrm{V}_{\mathrm{i}}\right)$ de $0,016 \mathrm{~mm} / \mathrm{s}$ para o primeiro minuto, com velocidade de infiltração estabilizando-se também logo em seguida $\left(V_{i}=0 \mathrm{~mm} / \mathrm{s}\right)$.

Os resultados mostram que as áreas de mata ciliar das duas áreas, com maiores teores de argila/silte, apresentaram comportamento muito próximo no processo de infiltração nas duas épocas do ano, com estabilização da infiltração nos primeiros minutos. Esses dados refletem o caráter argiloso do solo e a proximidade com os igarapés, com a água infiltrada provavelmente atingindo logo o nível freático raso, cuja profundidade variou de 0,55 m na época seca para $0,19 \mathrm{~m}$ no período chuvoso. Além disso, destaca-se o papel da vegetação no balanço de energia e no fluxo de água (TUCCI \& CLARKE 1997), evitando mudanças significativas nas condições hidrológicas ao longo do ano, como mostra a pequena variação na umidade do solo, nas duas épocas (25,5 para $28,9 \%$ na bacia do igarapé 54 , e de 29,75 para $32,9 \%$ no igarapé 7 ). 
Figura 2 - Curvas da taxa de infiltração para áreas de mata ciliar no igarapé 54 e igarapé 7 nos períodos de estiagem e de chuva e seus respectivos teores de umidade
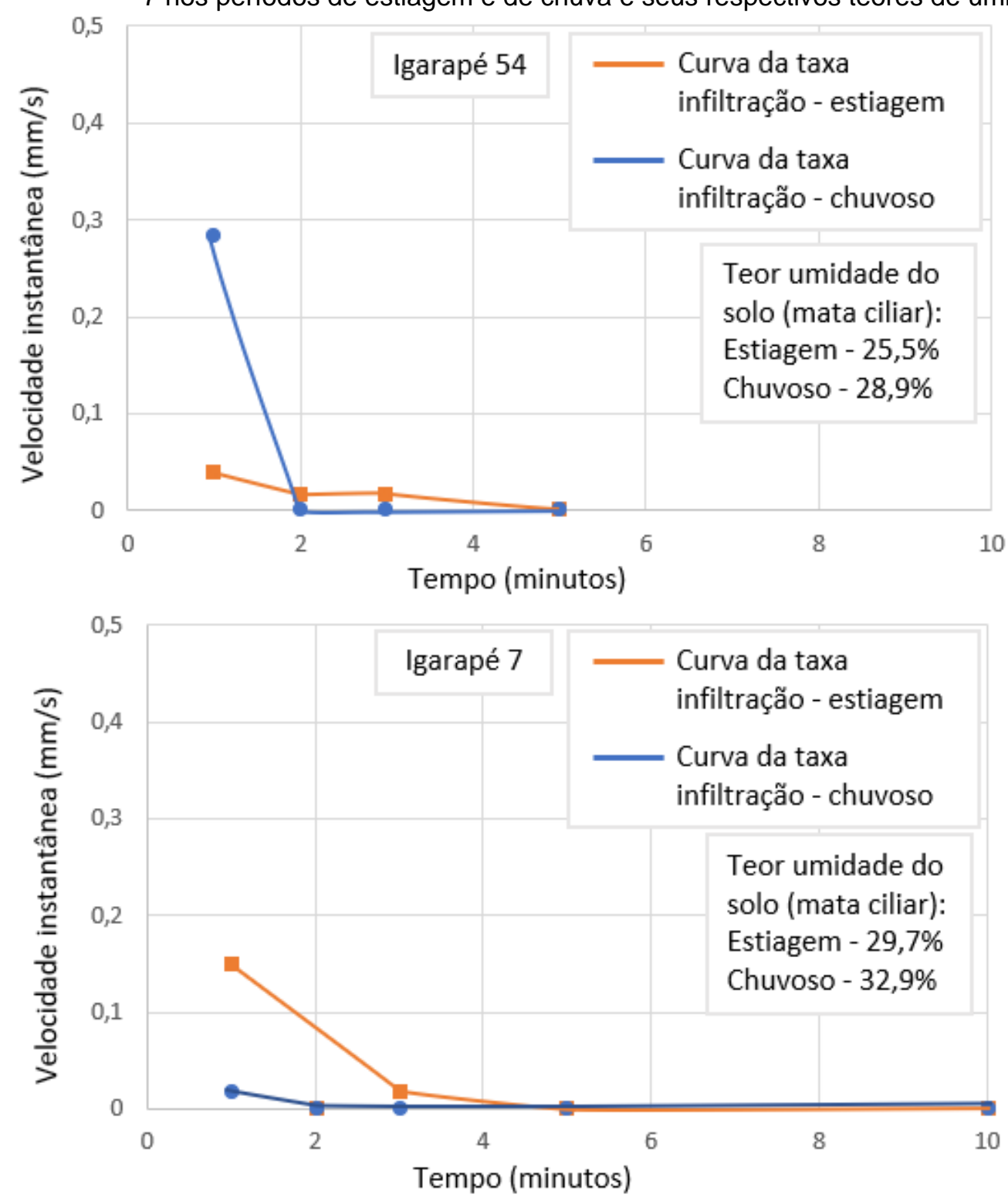

\subsection{Ensaios de Infiltração em Pastagem - Igarapé 54 e 7}

O ensaio feito no igarapé 54 no período de estiagem (Figura 3), com predomínio de solo argiloso (75,4\% de argila/silte) e teor de umidade do solo de 14,22\%, apresentou valor máximo de velocidade instantânea $\left(\mathrm{V}_{\mathrm{i}}\right)$ de $0,100 \mathrm{~mm} / \mathrm{s}$ e um mínimo de 0,028 mm/s, com velocidade de infiltração se estabilizando aos 60 minutos. No ensaio feito no período chuvoso (Figura 3), o teor de umidade do solo foi de $22,25 \%$ e a velocidade instantânea $\left(\mathrm{V}_{\mathrm{i}}\right)$ máxima de $0,116 \mathrm{~mm} / \mathrm{s}$, caindo rapidamente a partir do minuto 5 e estabilizando-se com valores negligenciáveis $(0,0008$ e $0,001 \mathrm{~mm} / \mathrm{s})$ a partir do minuto 40 . 
O ensaio feito no igarapé 7 no período de estiagem (Figura 3), cujo solo apresentou $29,46 \%$ de argila/silte e teor de umidade em torno de $8,7 \%$, apresentou valor máximo de velocidade instantânea $\left(V_{i}\right)$ de $0,083 \mathrm{~mm} / \mathrm{s}$ e mínimo de $0,002 \mathrm{~mm} / \mathrm{s}$, onde a velocidade de infiltração se estabilizou aos 90 minutos. No ensaio feito no período chuvoso (Figura 3), o valor do teor de umidade do solo elevou-se para $21,6 \%$ apresentando velocidade instantânea $\left(V_{i}\right)$ de $0,016 \mathrm{~mm} / \mathrm{s}$; a velocidade de infiltração nessa bacia se estabilizou logo no segundo minuto do ensaio $\left(V_{i}=0 \mathrm{~mm} / \mathrm{s}\right)$.

Os ensaios feitos nas áreas de pastagem no período de estiagem apresentaram comportamentos distintos aos feitos no período chuvoso. No primeiro caso, a velocidade de infiltração estabilizou-se aos 60 minutos na área do igarapé 54, e aos 90 minutos no igarapé 7. No período chuvoso a velocidade instantânea $\left(V_{i}\right)$ alcançou valores negligenciáveis logo nos primeiros minutos, nas duas bacias, refletindo a baixa capacidade de retenção de umidade na camada superficial do solo e a facilidade de evaporação da água retida pela pastagem, aumentando a refletividade e a temperatura do solo (SALATI, 1985). Esse fato é comprovado pela variação na umidade do solo, do período seco para o chuvoso, passando de 14,22 para $22,25 \%$, no igarapé 54 , e de 8,7 para $21,6 \%$ no igarapé 7. Além desse fator, também se destaca o papel da compactação causada pelo pisoteio do gado, reduzindo assim, portanto, a capacidade de infiltração.

Bruijnzeel (1996) relata a deterioração da capacidade de infiltração do solo por um conjunto de fatores, como o processo de aquecimento e secagem da camada superficial, o desaparecimento da matéria orgânica e das comunidades da fauna edáfica, erosão por impactos das gotas da chuva e selamento da superfície. Schuler (2003) sugere que esses distúrbios causados pela conversão de florestas podem originar uma camada de impedimento na superfície. 
Figura 3 - Curvas da taxa de infiltração para áreas de pastagem no igarapé 54 e igarapé 7 nos períodos de estiagem e de chuva e seus respectivos teores de umidade
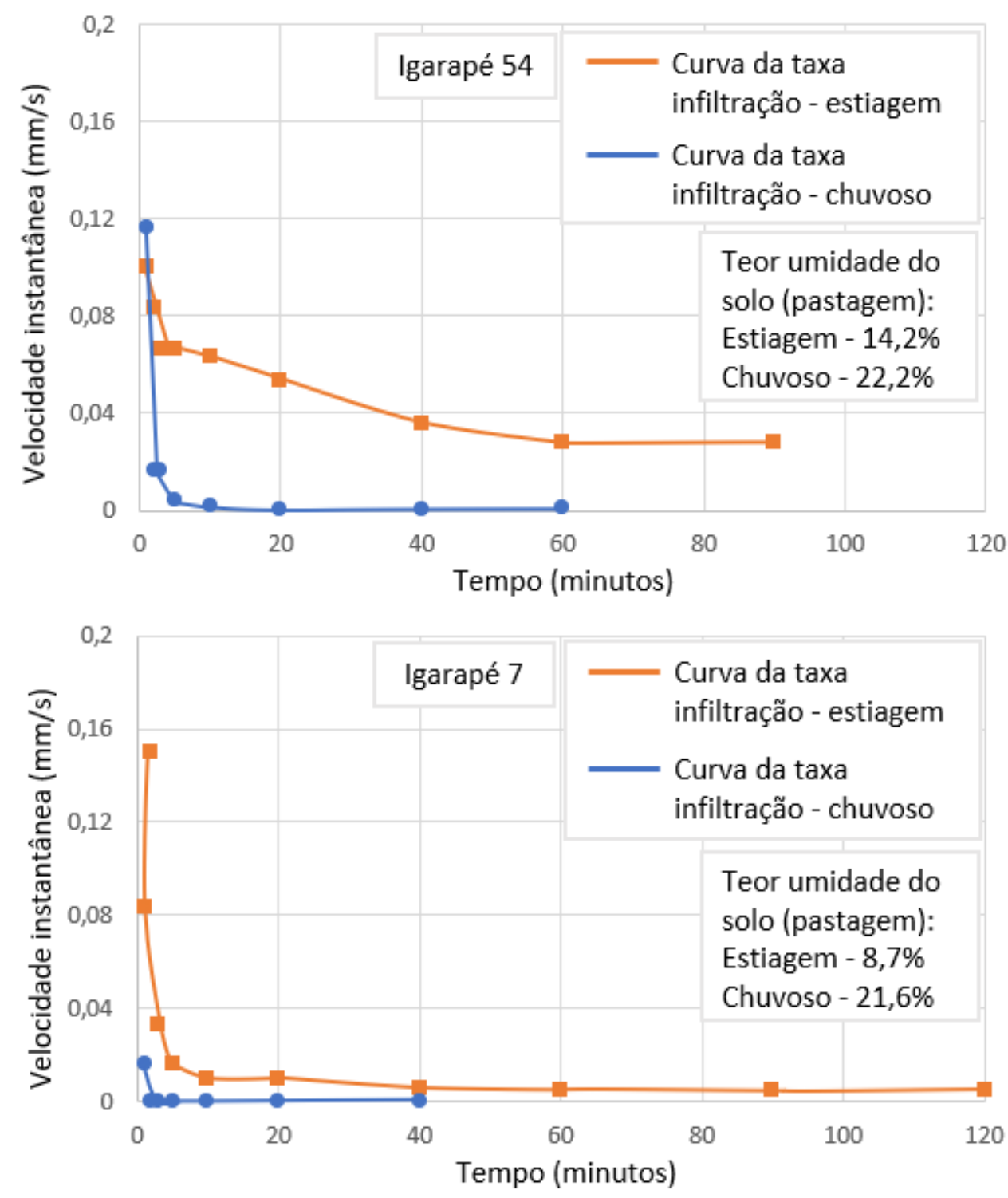

\subsection{Ensaios de Infiltração em Agricultura - Igarapé 54}

Na área de agricultura, avaliada apenas no igarapé 54 , o solo possui $54,6 \%$ de argila/silte. O ensaio no período de estiagem (Figura 4) apresentou valor máximo de velocidade instantânea $\left(\mathrm{V}_{\mathrm{i}}\right)$ de $0,700 \mathrm{~mm} / \mathrm{s}$ e mínimo de $0,050 \mathrm{~mm} / \mathrm{s}$, com a infiltração estabilizando-se a partir dos 60 minutos. Nessa época, o teor de umidade do solo foi de apenas $9 \%$. Já no período chuvoso, o valor máximo de velocidade instantânea $\left(\mathrm{V}_{\mathrm{i}}\right)$ foi de $0,083 \mathrm{~mm} / \mathrm{s}$ e o mínimo de $0,026 \mathrm{~mm} / \mathrm{s}$ (Figura 4). A infiltração se estabilizou próximo aos 60 minutos e o teor de umidade do solo foi de $16,9 \%$.

Nos ensaios feitos na área agricultura a velocidade de infiltração estabilizou-se aos 60 minutos, nos dois períodos. Nessa área, cujo solo apresenta 54\% de silte/argila, da 
época seca para a chuvosa o teor de umidade passou de 9 para $16,9 \%$, enquanto a velocidade instantânea $\left(\mathrm{V}_{\mathrm{i}}\right)$ variou refletindo a baixa umidade do solo associada ao recente uso do maquinário agrícola para revolver o terreno durante o plantio. Essa prática favorece o aumento temporário da capacidade de infiltração, devido à modificação da estrutura superficial e subsuperficial do solo. A interferência desse último fator é justificada pelo fato de na época em que foi feito o ensaio de infiltração (estiagem), essa área havia mudado recentemente de pastagem para área agrícola.

Figura 4 - Curvas da taxa de infiltração para área de agricultura apenas no igarapé 54 nos períodos de estiagem e de chuva e seus respectivos teores de umidade

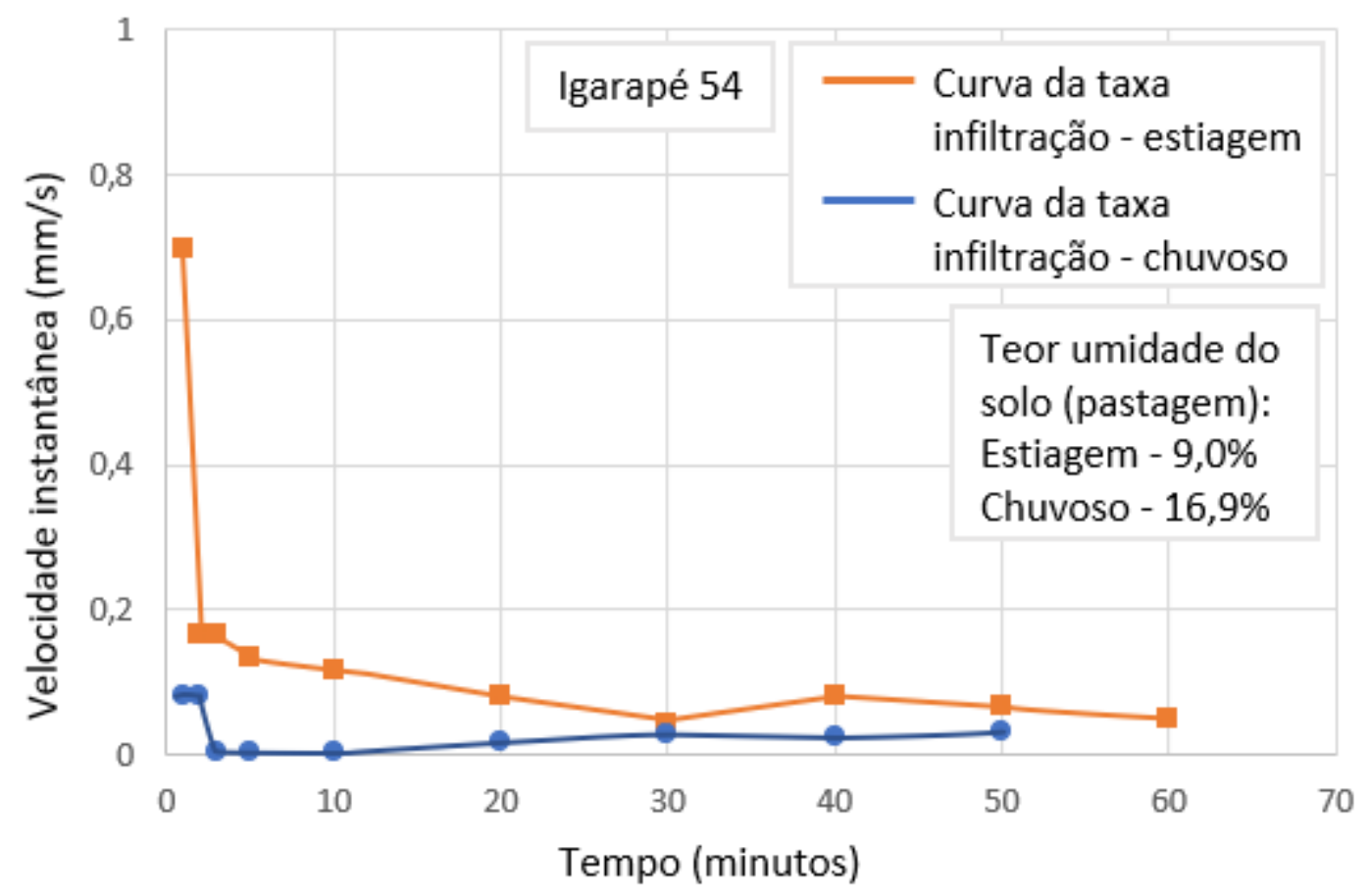

\section{CONCLUSÕES}

A partir dos resultados constatou-se a existência de uma estreita relação entre velocidade de infiltração, teor de umidade, textura e tipo de manejo do solo nas áreas estudadas (mata ciliar, pasto e agricultura). Os ensaios em áreas de mata ciliar nos igarapés 54 e 7 apresentaram valores muito próximos em períodos de estiagem e de chuva, refletindo a pouca profundidade do nível freático, o caráter argiloso do solo e o papel da vegetação no balanço da energia e do fluxo da água.

Os ensaios em áreas de pasto apresentaram valores distintos de um período para outro, refletindo a baixa capacidade de retenção de umidade na camada superficial do solo e o fato das áreas estarem desprotegidas, com solo compactado devido ao pisoteio do gado 
e a consequente redução da capacidade de infiltração. O ensaio na área de agricultura (apenas no igarapé 54) apresentou comportamento próximo nos dois períodos, com a taxa de infiltração estabilizando-se aos 60 minutos, porém, com expressivo decréscimo nos valores de velocidade instantânea $\left(\mathrm{V}_{\mathrm{i}}\right)$ de um período para outro.

Vale ressaltar que o uso de infiltrômetros de cilindros duplos podem resultar em estimativas relativas da taxa de infiltração da água no solo. Uma das causas seriam a ausência do efeito da compactação produzida pela água da chuva, a fuga do ar retido para a área externa aos tubos, e a provável deformação da estrutura do solo com a cravação dos tubos. Portanto, é recomendável que outras técnicas sejam concomitantemente utilizadas, para efeitos comparativos, como o uso de permeâmetros Philip-Dunne e de Guelph, e infiltrômetro de tensão.

\section{AGRADECIMENTOS}

Agradecimentos ao Instituto de Geociências da Universidade Federal do Pará e à Prof. Dra. Eliene Lopes de Souza.

\section{REFERÊNCIAS}

ASSOCIAÇÃO BRASILEIRA DE NORMAS TÉCNICAS. NBR 7217: Agregados - Determinação da composição granulométrica - Método de ensaio. Rio de Janeiro 1987. Disponível em: http://licenciadorambiental.com.br/wp-content/uploads/2015/01/NBR-7.217-

Determina\%C3\%A7\%C3\%A3o-da-composi\%C3\%A7\%C3\%A3o-granulom\%C3\%A9trica.pdf. Acesso em: 10 de set. 2018 .

ASTM D3385. Standard test method for infiltration rate of soils in field using double-ring infiltrometer. Annual book of ASTM standards, v. 4, n. 2. ASTM International, 2003. Disponível em: https://www.astm.org/Standards/D3385.htm. Acesso em: 15 de out. 2019.

BERTOL, I. et al. Water erosion on an Hapludox submitted to different soil managements under simulated rainfall. II - Nutrient and organic carbon losses. Rev. Bras. Ciênc. Solo. Viçosa, v. 28, n. 6, 2004. https://doi.org/10.1590/18069657rbcs20150111

BERTONI, J. \& LOMBARDI NETO, F. Conservação do solo. São Paulo: Ícone, 1990. 355p.

BOUWER, H. (1986). Intake Rate: Cylinder Infiltrometer. In: Methods of Soil Analysis, Part 1: Physical and Mineralogical Methods, Klute, A. (Ed.). SSSA, Wisconsin, p. 825-844. https://doi.org/10.2136/sssabookser5.1.2ed.c32

BRUIJNZEEL, L. A. Predicting the Hydrological Impacto $f$ Land Cover Transformation in the Humic Tropics: the Need for Integrated Research. In: GASH, J. H. C; NOBRE, C. A.; ROBERTS, J. M. e VICTORIA, R. L., eds. Amazonian deforestation and climate. C. England: John Wiley \& Sons, 1996 (Cap. 2). 
CAUDURO, F.A. \& DORFMAN, R. Manual de ensaios de laboratório e de campo para irrigação e drenagem. Porto Alegre, PRONI, IPH-UFRGS, 1986. 216 p.

COSTA, M.L. da; Angélica, R.S.; AVELAR, J.O.G. de. Outeiro e Mosqueiro: exemplos de evolução laterítica imatura. In: Simpósio de Geologia da Amazônia. [Anais...]. Belém-Sociedade Brasileira de Geologia Núcleo Norte. 1985.V.1.p 479-494.

CPRM. Serviço Geológico do Brasil. Paragominas: estudo de pesquisa e comprovação hidrogeológica. Programa de apoio a gestão territorial: Projeto informações geológicas do Estado do Pará. 1997. 31 p.

FEITOSA FAC, MANOEL FILHO J, FEITOSA EC AND DEMETRIO JGA. 2008. Hidrogeologia: conceitos e aplicações. 3. ed., Rio de Janeiro: CPRM/LABHID, 812 p. Disponível em:

http://rigeo.cprm.gov.br/sspui/bitstream/doc/14818/3/livro hidrogeologia conceitos.pdf. Acesso em: 16 ago. 2018.

GOÉS, A M. Estudos sedimentalógicos dos sedimentos Barreiras, Ipixuna e Itapecuru no Nordeste Paraense e Noroeste do Maranhão. Dissertação (Mestrado em Geologia)

Universidade Fedral do Pará, Belém. 1981. 55p. Disponível em:

http://repositorio.ufpa.br/jspui/handle/2011/8697. Acesso em: 14 fev. 2018.

GULLIVER, J.S., A.J. ERICKSON, AND P.T. WEISS (editors). (2010). Stormwater Treatment: Assessment and Maintenance. University of Minnesota, St. Anthony Falls Laboratory. Minneapolis, MN.

IBGE. Divisão de Geociências do Norte. Mapa Geomorfológico das Folhas SA. 23 Y-A e S A 23 Y-C. Belém, 1996 (Submetido a publicação). Disponível em:

https://biblioteca.ibge.gov.br/index.php/biblioteca-catalogo?view=detalhes\&id=69740. Acesso em: 10 set. 2018.

LIBARDI, P.L. Dinâmica da água no solo. Piracicaba: Snt, 1995. 497p.

MESNER, J. C. \& WOOLRIDGE L. CP. Maranhão Paleozoic Basin END Cretaceous Coastal Basin, North Brazil. Bull. Am. Ass. Petro. Geol., v.48, n 9. p.1475-1512, 1964.

https://doi.org/10.1306/BC743D99-16BE-11D7-8645000102C1865D

PINTO, A.; AMARAL, P.; SOUZA JR., C.; VERÍSSIMO, A.; SALOMÃO, R.; GOMES, G.; BALIEIRO, C. Diagnóstico Socioeconômico e Florestal do Município de Paragominas.

Relatório Técnico. Belém/PA: Instituto do Homem e Meio Ambiente da Amazônia - Imazon, 2009. $65 \mathrm{p}$.

RODRIGUES, T. E.; SILVA, R. das C.; SILVA, J. M. L. da; OLIVEIRA JUNIOR, R. C. de; GAMA, J. R. N. F.; VALENTE, M. A. Caracterização e avaliação da potencialidade dos solos e zoneamento agroecológico do município de Paragominas do Estado do Pará. Embrapa. 2002 a. 47 p. Disponível em: https://www.embrapa.br/busca-de-publicacoes//publicacao/408067/caracterizacao-e-classificacao-dos-solos-do-municipio-de-paragominasestado-do-para. Acesso em: 15 out. 2019.

SECTAM - SECRETARIA DE ESTADO DE CIÊNCIA E TECNOLOGIA E MEIO AMBIENTE DO PARÁ - SECTAM. Mapa de uso atual da terra do Município de Paragominas, Belém. 1996.

SHULER, A. E. Fluxos hidrológicos em microbacias com floresta e pastagem na Amazônia Oriental, Paragominas, Pará. Universidade do Pará. Tese (doutorado em Biologia), 2003. p. 6670. 
SOBRINHO, TEODORICO ALVES, VITORINO, ANTÔNIO C. T., SOUZA, LUIZ C. F. DE, GONÇALVES, MANOEL C., \& CARVALHO, DANIEL F. DE. Infiltração de água no solo em sistemas de plantio direto e convencional. Revista Brasileira de Engenharia Agrícola e Ambiental, v. 7, n. 2, p. 191-196, 2003. https://doi.org/10.1590/S1415-43662003000200001

STONE, L. F. \& MOREIRA, J. A. A. Efeitos de sistemas de preparo do solo no uso da água e na produtividade do feijoeiro. Pesq. agropec. bras. [online], v. 35, n. 4, p. 835-841, 2000.

https://doi.org/10.1590/S0100-204X2000000400022

TUCCI, C. E. M. \& CLARKE R. T. Impacto das mudanças da cobertura vegetal no escoamento: revisão. Revista Brasileira de Recursos Hídricos. v.2, p. 135 - 152, jan./jun. 1997.

https://doi.org/10.21168/rbrh.v2n1.p135-152

TUCCI, C. E. M. (Org.). Hidrologia: ciência e aplicação. 3. ed. Porto Alegre: Editora da UFRGS: ABRH, 2004. 943 p. https://doi.org/10.3923/ijss.2012.168.176

WALSH, E., AND MCDONNELL, K.P. The influence of measurement methodology on soil infiltrationrate. International Journal of Soil Science. v.7, n. 4, p. 168-176, 2012.

https://doi.org/10.3923/ijss.2012.168.176 